\title{
Evoking emotions in virtual reality: schema activation via a freeze-frame stimulus
}

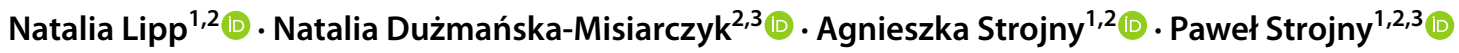

Received: 9 August 2019 / Accepted: 17 June 2020 / Published online: 3 July 2020

(c) The Author(s) 2020

\begin{abstract}
Virtual reality can be used for educational purposes, particularly in demanding professions such as firefighting. Such virtual training may be useful for preparing trainees for distress, fear, or frustration experienced during real rescue operations. Evoking cognitive schemas, especially of other people, during training appears to be crucial as well, as the greatest stressors in the firefighting profession are social. Based on interviews with firefighters, two types of people (children and young women) were chosen as stimuli in the research design. In an experimental study with three iterations, the stimuli designed to evoke the schema of a significant other were implemented in a virtual reality simulator to evoke a cognitive schema in firefighters through emotions (positive and negative) and several dimensions of stress. The first iteration of the study did not yield expected results, as the stimulus (a child's toy) was not as suggestive and vivid as it was expected. In the second attempt, the stimulus was improved and evoked feelings of challenge, harm, and loss in the participants. In the third iteration, the stimulus was changed once more (to a white dress) and this time it evoked negative emotions of fear, anger, guilt, and sadness. However, after correcting for multiple comparisons, only results regarding emotional response remained statistically significant. The results are discussed in light of cognitive schemas' activation, and perspectives for further research in this scope are proposed. Due to research outcomes, the issues of manipulation checks in experimental psychology and limitations of the VR technology are taken into consideration.
\end{abstract}

Keywords Virtual reality $\cdot$ Serious games $\cdot$ Cognitive schema $\cdot$ Emotions $\cdot$ Training $\cdot$ Simulation

\section{Introduction}

\subsection{Virtual training}

Firefighting is considered to be one of the most dangerous professions. According to the State Fire Service of Poland, 1820 firefighters were injured (including one fatal injury)

Electronic supplementary material The online version of this article (https://doi.org/10.1007/s10055-020-00454-6) contains supplementary material, which is available to authorized users.

Natalia Lipp

natalia.lipp@student.uj.edu.pl

1 R\&D Unit, Nano Games sp. z o.o., ul. Gromadzka 101, 30-719 Kraków, Poland

2 Institute of Applied Psychology, Faculty of Management and Social Communication, Jagiellonian University, ul. Stanisława Łojasiewicza 4, 30-348 Kraków, Poland

3 R\&D Unit, Simpro sp. z o.o., ul. Gromadzka 101, 30-719 Kraków, Poland during rescue operations in 2018 (The State Fire Service of Poland 2018). Therefore, it is not surprising that firefighters' training is also demanding and extensive. In Poland, basic firefighter education includes 177 training days, of which 78 days $(622 \mathrm{~h}$ ) are devoted to didactic classes and 90 days to professional practice. As part of their apprenticeship, cadets are required to serve a minimum of 28 full-day shifts (i.e., $24 \mathrm{~h}$ per one shift). The didactic classes are conducted in the form of lectures and practical classes concerning such issues as occupational health and safety, service in the National Fire Service, psychological aspects of rescue operations, the physical and chemical phenomena, extinguishing equipment, firefighting tactics, rescue tactics, and physical education (The State Fire Service of Poland 2016). Such field training is expensive and difficult to manage. Two-year training for one cadet costs about $\$ 36,600$ (Supreme Audit Office 2012). In this light, it seems that training in virtual reality (VR) seems to be a valuable complement to the comprehensive education of firefighters. 
This solution is not particularly new as professional VR simulators have been successfully used in the fire service. In a literature review, Williams-Bell et al. (2015) describe more than 20 examples of the use of virtual reality, video games, and serious games for firefighters. Such simulators can be used to train managing skills, rescue procedures, or safety behaviors (Williams-Bell et al. 2015). Moreover, simulations are also created to illustrate the process of fire and smoke propagation (Beaudoin et al. 2001). Virtual reality can provide the user not only with visual and audio stimuli, but also with haptic or heat sensations (Han et al. 2018). Such solutions have many advantages in the educational field, i.e., they are a safe and profitable alternative to traditional training (Williams-Bell et al. 2015), and they have high face validity and allow for customization and repetition of the training scenarios (Haque and Srinivasan 2006; Johnsen et al. 2005). This is particularly important because of the high number of injuries (31\% of all injuries) during firefighters training (Jahnke et al. 2013).

One of the reasons for high interest in VR training is that professional simulators implement solutions from the gaming industry, namely game design elements (Deterding et al. 2011) - patterns and mechanics which make training simulators more engaging (Fabricatore et al. 2014). Furthermore, it is argued that massive multiplayer gaming (MMPG) technology could be effective for training purposes by providing scenarios based on planning, coordination, teamwork, and decision making under stress (Alexander et al. 2005) —all of which correspond with the everyday work of firefighters. In addition, the impact of video games on effective learning has been repeatedly demonstrated empirically (e.g., Graafland et al. 2012; Hoffman and Nadelson 2010; Rosser et al. 2007). Playing video games arouses positive affect, satisfaction, and joy, all of which are related to intrinsic motivation and reaching goals, but only if the game is challenging (Hoffman and Nadelson 2010). To learn effortlessly, playing a game should evoke a high level of excitement (Graafland et al. 2012). Therefore, game-based simulations seem to be a promising training method.

Moreover, Alexander et al. (2005) argued that one of the basic conditions of knowledge or skills transfer is psychological fidelity, which is defined as "the degree to which the simulation replicates the psychological factors (i.e., stress, fear) experienced in the real-world environment" (Alexander et al. 2005, p. 4). Psychological fidelity provides essential elements that encourage users to become emotionally involved (Brackney and Priode 2017). Therefore, there is a possibility that virtual environments may be psychologically compatible enough with the real ones to produce meaningful engagement in the users (Evans 2019).

Regarding VR simulators for fire service, training this compatibility (or psychological fidelity) appears to be crucial because of the daily routine full of stressors which may elicit negative emotions. Studies show that during rescue operations firefighters may experience a high level of distress, feeling of powerlessness, fear, sadness, aggression, annoyance, and frustration (Brooks et al. 2016; De Soir et al. 2012; Gormley et al. 2008). Eventually, commonly experienced negative emotions may lead to burnout, depression, or even posttraumatic stress disorder, which firefighters are particularly vulnerable to (Carey et al. 2011; Wagner et al. 2010; Lourel et al. 2008). There might be also short-term consequences of experiencing negative emotions during a rescue action such as injuries, low efficiency, and freezing reaction (Katsavouni et al. 2016; Smith et al. 2018; Ly et al. 2017). Taking into consideration the role of negative emotions in the fire service, it seems that designing a training during which firefighters experience the same emotional states as in a real action could contribute to better recall of the procedures and-in consequence- - to better performance. Such emotional states could be evoked using specific stimuli, aimed at increasing the psychological fidelity of the scenario of virtual training.

The attempt of evoking negative emotions in a virtual training environment is consistent with the concept of mood state-dependent memory which "implies that what one remembers during a given mood is determined in part by what one learned (or focused on) when previously in that mood" (Blaney 1986, p. 229). The match between the encoding and retrieval mood depends on the intensity of an emotional state involved during the encoding - the more intense mood during learning, the better recalling and remembering. Additionally, learning and remembering are affected by environmental context. Information encoded during real-life events is better remembered than information gained in the course of intentional or incidental learning (Ucros 1989).

\subsection{Schema activation and freeze frames}

Evoking emotional states in the context of the mood-state dependency effect (Blaney 1986) mentioned in Sect. 1.1 appears to be not an easy task. It could be the case that photo-realistic images and high-fidelity sounds provided by VR may evoke emotional reactions, just like in real-life situations. Regarding the goal of firefighters' training, this approach may be considered useful. Developing a photorealistic virtual environment is however still expensive and extremely laborious. As a response to these issues, we believe that there is another, more sophisticated (and at the same time, significantly less expensive and laborious) method of evoking the emotional states desired by the trainer. This approach is based on previous experiences of the trainee or content embedded in their culture, namely cognitive schemas (Tesser and Leone 1977) they have acquired.

A cognitive schema consists of structured knowledge and experiences, and it functions as a relative reference point for 
information. Every new information received by an individual is assessed in terms of consistency with the existing schema. If information is evaluated as consistent with the existing schema, it is incorporated into cognition. On the contrary, inconsistent information may be ignored (Tesser and Leone 1977; Fiske and Taylor 1991; Hommel 1996; Axelrod 1973). Therefore, existing schemas determine how the observed phenomena are interpreted and understood. According to Derry (1996), there is one more function of schemas-the memory object activation, which is connected with specific information. It means that some stimuli may trigger particular memories, including emotions and behaviors related to them.

We believe that evoking emotions in firefighters is possible by activating a specific schema and therefore decided to test whether a schema can be effectively activated in VR. In particular, we decided to focus on the schema of a significant other, which is defined as a prototype-based theme (Wyer et al. 1984). The schema of a significant other is activated and applied to a new person if they possess a particular attribute similar to somebody already known (Wyer et al. 1984). According to Andersen et al. (1996), the schema of a significant other is always ready to be activated by processing transient contextual cues.

One of the reasons why we decided to focus on this schema is the importance of social aspects in the firefighter profession. The greatest stressors include events such as witnessing death of a co-worker, suffering a minor injury by the firefighter themselves, and rendering aid to adult stabbing victim, friend or relative, seriously injured adolescent (Beaton et al. 1998) - most of them are related to other people. Another reason is that, as reported by Woodall (1997), during a rescue action "the firefighter almost immediately made a tie, a connection, with the victim and a person (usually their child, significant other, or parent) close to them in their personal life" (Woodall 1997, p. 157). Moreover, in a literature review, Brooks et al. (2016) pointed out that strong identification with a victim may be connected to intrusive thoughts and symptoms of PTSD. Tendency to identify a victim as a friend could cause firefighters to be more emotionally involved. These reports seem to be consistent with the results of our preliminary qualitative study (Strojny et al. 2018) in which we interviewed firefighters and paramedics about rescue operations. Eighteen partially structured interviews with rescuers from the State Fire Service were conducted to collect examples of stressful situations. Interpretative phenomenological analysis (IPA; Smith and Shinebourne 2012) was used to approach the interviews. The participants reported many highly emotional and stressful events, for example:

I think that you act differently with children, because (...) that child has just begun its life. So it is only at the first stage [of life], and then suddenly this life turns upside down. (...) And children are delicate. And many firefighters, I have noticed, are most scared of helping newborns, or children old up to three, four years. (...) Because then everybody suddenly imagines their child.

(...) There was a woman driving to some hen party. (...) Her head was split open, they say that some of her brain... that... it made a hole in her head. And we arrived - at that moment she had already been carried into the ambulance by the firefighters who had come first (...). You look and you see, say, that her clothes are hanging. Some elegant clothes, shoes, everything, she was driving somewhere, someone was waiting for her and you get such thoughts. Somebody was waiting for her, she didn't arrive, and someone is expecting her soon and will start to worry that she hasn't come.

The qualitative analysis of the interviews indicates that during rescue operations firefighters are often surprised by objects which are unexpected in a particular situation, but are nonetheless considered regular, everyday items (e.g., an outfit for a bachelorette party). Such objects can evoke mixed emotions or even cognitive dissonance. Firefighters repeatedly report that such situations cause them to halt their well-learned routines and make it momentarily impossible to take action.

These results seem to be consistent with several studies that have shown that rescuing a child, a friend, or a family member is a very stressful event (De Soir et al. 2012; Katsavouni et al. 2016; Regehr et al. 2003). Inability to take action may stem from a response to an acute stress, namely a freezing reaction (Ly et al. 2017). Threat-induced freezing is characterized by heart rate deceleration and immobility. However, it seems to serve as a cognitive preparation for taking action rather than an inability to act (Gladwin et al. 2016). Acute stress inducing such reaction may be caused by different stimuli as well. It is possible that even everyday objects (e.g., a toy, an outfit for a bachelorette party) can trigger such reaction by activating the cognitive schema (Hagenaars et al. 2014; Azevedo et al. 2005). Therefore, we called them "freeze-frame" situations or stimuli. This kind of stimuli corresponds well with the idea of Woodall's (1997) mental bridge - a connection between a firefighter and a victim, and it appeared implementable in our training VR simulator.

We decided to explore the possibility of evoking desired psychological states (as reported by firefighters during interviews and based on previous studies on the topic) using two "freeze frames" designed entirely based on the previously cited qualitative study. Namely, the first one was an accident in which the victim could have been a child—it was reported by many firefighters when asked about particularly 
stressful situations. Children are a special type of victimthe reaction of caretaking triggered by a child is evolutionary (Glocker et al. 2009; Miesler et al. 2011). Firefighters report that when the victim is a child, they immediately think of children they know (Monteiro et al. 2013). The second freeze frame we chose was the situation described in the above quotation-a car accident involving a bride-to-be which was selected due to the reported strong impact on the emotions of a participant of the qualitative study. Noticing a dress in the crushed car caused the rescuer to stop the procedure, maybe even to freeze. His reaction-reflecting on the personal life of the victim instead of acting-could be explained by activation of the cognitive schema of a significant other, caused by nothing more than just an elegant outfit. In the present study, the bachelorette's outfit was changed to a white wedding dress laying on the backseat of the car, as a wedding dress appeared to be more unequivocal in interpretation than elegant clothes. It is noteworthy that both situations were designed without the participation of virtual agents representing the mentioned people (bride, child). Only the objects aimed at activating the appropriate cognitive schemas were put on the virtual scene.

To conclude, based on the literature review and the qualitative study, we formulated the following research hypotheses:

1. Placing freeze-frame objects in the simulation would lead to an increase in negative emotions (fear, anger, guilt, sadness).

2. Placing freeze-frame objects in the simulation would lead to a decrease in positive emotions (joy, love).

3. Placing freeze-frames objects in the simulation would strengthen the experience of situational stress (in the following aspects: harm/loss, challenge activity, challenge passivity, and threat).

To test these hypotheses, we implemented the freezeframe stimuli in a VR training simulator.

\section{Study I}

\subsection{Materials and methods}

In this paper, a part of an experimental study with four iterations overall is described. The main goal of the study was to assess the influence of changes implemented in a VR training simulator on participants' subjective feelings and their several physiological parameters (for more detailed information about the design of the study and all methods used, see Online Resource 1).

For this report, we present data from two groups: the freeze-frame experimental condition and the control condition in the first, second, and third iteration of the study, respectively. The presented research was accepted by the Ethical Committee at Jagiellonian University, at the Institute of Applied Psychology.

\subsubsection{Participants}

The participants of the study were recruited at the College of the State Fire Service and firefighting units in Cracow (Poland); all of them had undergone at least 1 year of training and had participated in real-life rescue operations. Sixty firefighters (professionals: $n=14$, or cadets: $n=46$ ) participated in the described part of the study: 59 of them were men and one was a woman; their age ranged between 19 and $40(M=23.77, \mathrm{SD}=5.51)$. The length of service ranged between 1 and 19 years (cadets: $M=1.13, \mathrm{SD}=0.62$; professionals: $M=9.50, \mathrm{SD}=4.36$ ).

\subsubsection{Procedure}

The experimental procedure was identical for all three iterations and is described in this section. Any changes in the stimuli will be noted in the corresponding sections. For the experiment, the HTC Vive VR hardware was used; the participants were given a head-mounted display (HMD), two wireless handheld controllers, and headphones. HTC Vive HMD has a 110-degree field of view and a refresh rate of $90 \mathrm{~Hz}$. The HMD was connected to a PC with a $3.40 \mathrm{GHz}$ Intel Core i7 processor, $16 \mathrm{~GB}$ of RAM, and an NVIDIA GeForce GTX 1080 graphics card. The simulator used in the study was developed using the Unity engine. The simulated scenario included a car crash on an intersection in a small town. A screenshot of the simulated environment is presented in Fig. 1.

Six victims were present at the scene of the incident. The participants could perform several actions, i.e., they could walk around the VR environment (at walking speed in a safe space designated using room setup tools provided by the producer of the VR set) or move instantly from one place to another, chosen one, using a "teleportation" mode. Therefore, there were two cases of movement speed: If the teleportation mode was chosen, the change of place in the virtual environment was instant, so it had no speed per se. If the participant decided to walk, the movement speed in VR was the same as walking speed in the real world. They could also secure the accident site using bollards and open the car doors. The possible interactions with victims were: conducting the SAMPLE interview, ${ }^{1}$ checking several physical

\footnotetext{
${ }^{1}$ SAMPLE is an acronym for six basic questions in a medical assessment: symptoms, allergies, medications, past medical history, last oral intake, and events leading up to present injury.
} 
Fig. 1 An overview of the simulated environment presenting a car crash accident on the road intersection involving six victims
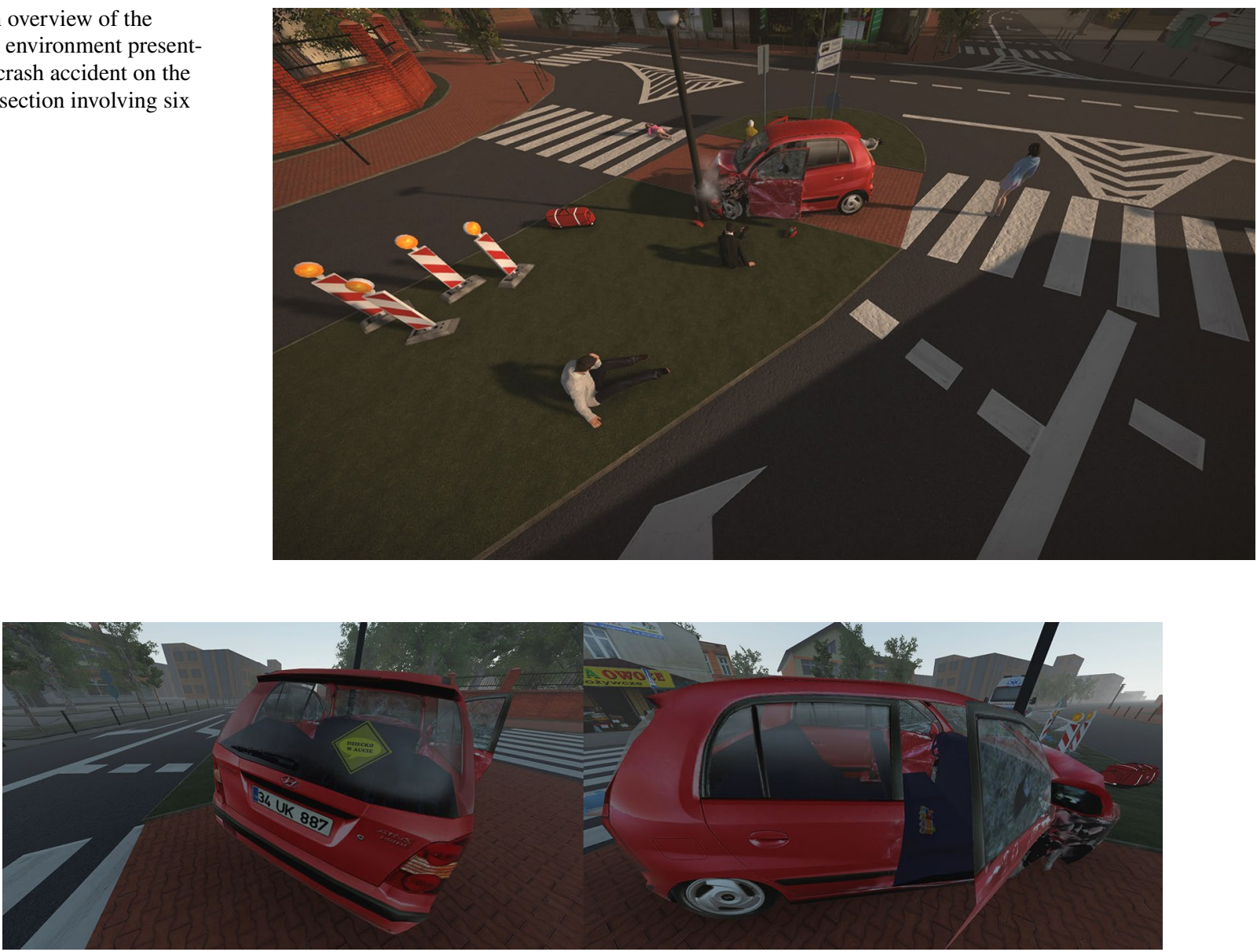

Fig. 2 The freeze-frame stimulus in the first iteration of the study. The left panel presents the rear window with the "baby on board" sticker. The right panel presents a side view of the open car and the child's toy on the front seat

parameters (pain reaction, breathing, airways, and capillary recurrence), covering the person with a blanket, and dressing the wounds. Only some of the objects presented at the scene were interactive (bollards and car doors; one could also interact with the virtual agents). Other objects (e.g., toy) could not be moved.

In this iteration, in the experimental condition, there was a sticker on the back window of the car saying "DZIECKO W AUCIE" ("child in the car"/"baby on board" in Polish). A toy-a wooden train-was laying on the front passenger seat. The location of the stimulus was chosen based on the fact that during a rescue action the car should be examined. In the control condition, no such item was present. Sample screenshots of this stimulus are presented in Fig. 2.

Upon arrival at the laboratory, the participants gave an informed consent in accordance with the Declaration of Helsinki, were briefly interviewed, and equipped with the apparatus for measuring several physiological variables. For the experimental task, the participants were asked to conduct a 5-min rescue action in the aforementioned VR simulator. They were asked to adhere to the procedure described in the regulations of the National Firefighting and Rescue System for the State Fire Service in Poland (Zasady organizacji ratownictwa medycznego w Krajowym Systemie RatowniczoGaśniczym 2013). After the experimental task, the participants completed a set of questionnaires that were administered using the tool provided by SurveyMonkey. ${ }^{2}$

\subsubsection{Measures}

The questionnaires used in the study are described in this section. In this paper, we focus on measuring the affective state and stress experienced by the individual. ${ }^{3}$

The Self-Assessment Manikin (SAM; Bradley and Lang 1994) is a pictorial questionnaire that allows assessment of emotional responses to stimuli in three fundamental dimensions: valence, arousal, and dominance. The Scale

\footnotetext{
2 www.surveymonkey.com.

${ }^{3}$ For the description of other methods, see the Supplementary Mate-
} rials. 
Table $1 T$ test results comparing the experimental and control group on emotions, affect, and stress in the first iteration of the study

\begin{tabular}{|c|c|c|c|c|c|c|c|c|}
\hline & \multicolumn{2}{|c|}{ Experimental } & \multicolumn{2}{|c|}{ Control } & \multicolumn{3}{|l|}{$t$ test } & \multirow[t]{2}{*}{ Cohen's $d$} \\
\hline & $M$ & SD & $M$ & SD & $t$ & $d f$ & $p$ & \\
\hline \multicolumn{9}{|c|}{ Self-Assessment Manikin } \\
\hline Valence & 7.20 & 1.24 & 7.03 & 1.82 & 0.41 & 58 & 0.681 & 0.11 \\
\hline Arousal & 3.73 & 1.01 & 3.8 & 1.51 & 0.20 & 58 & 0.842 & 0.05 \\
\hline Dominance & 5.87 & 1.36 & 6.00 & 1.58 & 0.35 & 58 & 0.727 & 0.09 \\
\hline \multicolumn{9}{|l|}{ Scale of Emotions } \\
\hline Joy & 2.34 & 1.30 & 2.74 & 1.34 & 1.17 & 58 & 0.245 & 0.3 \\
\hline Love & 2.49 & 1.03 & 2.52 & 1.08 & 0.09 & 58 & 0.927 & 0.03 \\
\hline Fear & 2.47 & 1.05 & 2.13 & 1.15 & 1.17 & 58 & 0.246 & 0.31 \\
\hline Anger & 1.58 & 0.71 & 1.45 & 0.75 & 0.71 & 58 & 0.482 & 0.18 \\
\hline Guilt & 1.61 & 0.50 & 1.40 & 0.67 & 1.36 & 58 & 0.18 & 0.36 \\
\hline Sadness & 1.70 & 0.66 & 1.49 & 0.69 & 1.19 & 58 & 0.237 & 0.31 \\
\hline \multicolumn{9}{|c|}{ Stress Appraisal Questionnaire } \\
\hline Harm/loss & 0.23 & 0.34 & 0.26 & 0.50 & 0.23 & 58 & 0.822 & 0.07 \\
\hline Challenge activity & 1.62 & 0.64 & 1.46 & 0.66 & 0.96 & 58 & 0.342 & 0.25 \\
\hline Challenge passivity & 1.81 & 0.63 & 1.68 & 0.62 & 0.82 & 58 & 0.413 & 0.21 \\
\hline Threat & 0.36 & 0.49 & 0.30 & 0.45 & 0.46 & 58 & 0.648 & 0.13 \\
\hline
\end{tabular}

${ }^{*} p<0.05 ; * * p<0.01 ; * * * p<0.001$ of Emotions (SoE, Wojciszke and Baryła 2005) is used to measure the intensity of six basic emotions: joy, love, fear, anger, guilt, and sadness. The questionnaire was validated by its authors (Wojciszke and Baryła 2005), and it reveals high psychometric properties. The internal consistency was evaluated by the authors of the questionnaire (Wojciszke and Baryła 2005) with Cronbach's alpha. The coefficients for all six subscales were as follows: $\alpha=0.81$ for joy, $\alpha=0.82$ for love, $\alpha=0.80$ for fear, $\alpha=0.85$ for anger, $\alpha=0.55$ for guilt, and $\alpha=0.86$ for sadness. ${ }^{4}$ The Stress Appraisal Questionnaire (SAQ; Włodarczyk and Wrześniewski 2010) was used to measure situational stress, which can be described with the following dimensions: harm/loss, challenge activity, challenge passivity, and threat. The psychometric evaluation of the questionnaire revealed satisfying internal consistency coefficients (Cronbach's alpha for: harm/loss $\alpha=0.80$, challenge activity $\alpha=0.71$, challenge passivity $\alpha=0.76$, and threat $\alpha=0.90$; Włodarczyk and Wrześniewski 2010). A manipulation check was administered as well to check whether the participant had seen the freeze-frame stimuli. The participants were asked whether they had seen the following objects: dog, drone, bystanders, policeman, and toy. Some of the objects were stimuli in other experimental conditions, and some of them were masking items.

\footnotetext{
4 The authors of the Scale of Emotions evaluated its properties on four different groups of participants. Given indicators refer to the group which is the most similar to our participants-young males in their education period. The Cronbach's alpha coefficient is low for the guilt subscale for the referred group; however, in a similar group (university students) it increases to 0.75 .
}

\subsection{Results}

Firstly, the manipulation check in the experimental group was evaluated. It was discovered that among 30 participants in this group, only three of them $(10 \%)$ declared that they had seen the freeze-frame stimulus. Moreover, not surprisingly, no significant changes were discovered between the freeze frame and the control group regarding the affective state and emotions (see Table 1; for raw data see the Online Resource 2). In Table 1, the effect sizes for each comparison are reported (Cohen's $d$; Cohen 1988, 1992). The Cohen's $d$ coefficient was calculated according to the following formula:

$d=\frac{\left(M_{\text {control }}-M_{\text {experimental }}\right)}{\left.\left.\sqrt{\left(\left(\mathrm{SD}_{\text {experimental }}^{2}\right.\right.}+\mathrm{SD}_{\text {control }}^{2}\right) / 2\right)}$

According to Cohen's (1992) guidelines, thresholds of 0.2 (small), 0.5 (medium), and 0.8 (large) are suggested to be used for interpreting $d$ values.

\subsection{Conclusions}

The results of the first iteration of the study led us to the conclusion that stimuli implemented in the VR simulator should be chosen and placed in the virtual environment more carefully. More effort should be put in ensuring that the crucial stimulus would be visible to all participants, regardless of what route or order of actions they took. The lack of differences between the two groups in terms of affect 


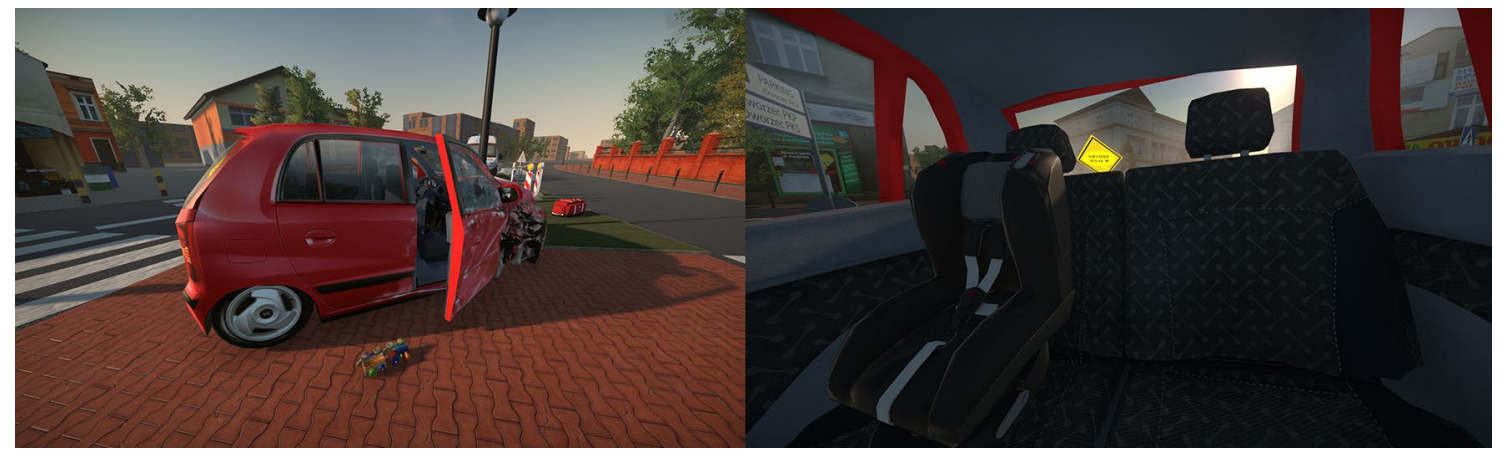

Fig. 3 The freeze-frame stimuli in the second iteration of the study. The left panel presents a child's toy near the crashed car. The right panel presents the car's interior and the child seat in it

and emotions most probably stemmed from the fact that the stimulus was not seen by the participants; therefore from their perspective, the conditions did not differ at all.

Taking these observations into consideration, we decided to improve the quality and accessibility of our freeze-frame stimulus. We decided to work further with the suggestion of the child being present at the scene and to add more relevant items to the simulated environment.

\section{Study II}

\subsection{Materials and methods}

\subsubsection{Participants}

Fifty-five firefighters (professionals: $n=9$, or cadets: $n=46$ ) participated in the described part of the study: 54 of them were men and one was a woman; their age ranged between 19 and $40(M=22.82, \mathrm{SD}=4.61)$. The length of service ranged between 1 and 19 years (cadets: $M=1.13, \mathrm{SD}=0.62$; professionals: $M=9.44, \mathrm{SD}=5.64)$. They were the same individuals as in the first iteration, and the experimental conditions were kept consistent. Due to the absence of specific participants or their refusal to participate in the study, the descriptive statistics are different than in the first iteration.

\subsubsection{Procedure}

In the second iteration of the study, several improvements were made in the general design of the simulator. Specifically, the sounds were made more appropriate (e.g., sounds of passing cars and injured people moaning in pain were added). The model of the car was made more realistic (more detailed inside, thicker doors), and animations of the victims were added (while checking airways the victims opened their mouths, one of the victims would lose consciousness $40 \mathrm{~s}$ after engaging in an interaction with her).
Moreover, a change in the toy stimulus was made based on the results of the previous iteration. The toy was moved to the outside of the car; also, a child seat was added to the back of the car (it was visible from the outside of the car wreck, but it could not be moved from this place). Apart from that, the stimuli remained the same as in the first iteration. Sample screenshots of the simulator are presented in Fig. 3.

A slight change was made regarding the administration of the questionnaires. From this iteration on, a Python script written in PsychoPy (Peirce 2007, 2009) was used as a tool for administering the self-report measures.

\subsubsection{Measures}

No changes were made in the self-report measures used in this iteration of the study. The questionnaires are described in Sect. 2.1.3.

\subsection{Results}

The manipulation check revealed that 16 out of $26(61.5 \%)$ participants in the experimental condition had seen the stimulus. It was decided that such a number was enough to compare the two conditions in terms of affect and emotions, without excluding observations. Significant differences were detected for two stress-related variables. The challenge-activity and harm/loss dimensions of stress were experienced more strongly in the experimental group (see Table 2; for raw data see the Online Resource 2). Effect sizes for the aforementioned variables are of moderate strength (for challenge activity: $d=0.74$, for harm/loss: $d=0.6$ ).

We also decided to use a correction for multiple comparisons. Due to a large number of comparisons, the Benjamini-Hochberg procedure was chosen. This correction has more power than the Bonferroni and Sidak procedures when more than three comparisons are made (Benjamini and Hochberg 1995). This stepwise procedure sorts the obtained 
Table $2 T$ test results comparing the experimental and control group on emotions, affect, and stress in the second iteration of the study

\begin{tabular}{|c|c|c|c|c|c|c|c|c|}
\hline & \multicolumn{2}{|c|}{ Experimental } & \multicolumn{2}{|c|}{ Control } & \multicolumn{3}{|l|}{$t$ test } & \multirow[t]{2}{*}{ Cohen's $d$} \\
\hline & $M$ & SD & $M$ & SD & $t$ & $d f$ & $p$ & \\
\hline \multicolumn{9}{|c|}{ Self-Assessment Manikin } \\
\hline Valence & 6.27 & 1.54 & 6.66 & 1.65 & 0.89 & 53 & 0.376 & 0.24 \\
\hline Arousal & 3.69 & 1.35 & 3.66 & 1.61 & 0.09 & 53 & 0.927 & 0.02 \\
\hline Dominance & 5.35 & 1.06 & 5.66 & 1.32 & 0.95 & 53 & 0.345 & 0.26 \\
\hline \multicolumn{9}{|l|}{ Scale of Emotions } \\
\hline Joy & 2.50 & 1.11 & 2.68 & 1.31 & 0.55 & 53 & 0.584 & 0.15 \\
\hline Love & 2.34 & 0.87 & 2.34 & 1.04 & 0.001 & 53 & 0.999 & 0.00 \\
\hline Fear & 2.31 & 1.17 & 2.08 & 0.89 & 0.83 & 53 & 0.413 & 0.22 \\
\hline Anger & 1.66 & 0.47 & 1.71 & 0.82 & 0.24 & 45.34 & 0.813 & 0.07 \\
\hline Guilt & 1.65 & 0.73 & 1.58 & 0.80 & 0.37 & 53 & 0.713 & 0.09 \\
\hline Sadness & 1.75 & 0.81 & 1.43 & 0.53 & 1.74 & 53 & 0.088 & 0.47 \\
\hline \multicolumn{9}{|c|}{ Stress Appraisal Questionnaire } \\
\hline Harm/loss & 0.45 & 0.57 & 0.17 & 0.34 & 2.19 & 41.60 & $0.035^{*}$ & 0.60 \\
\hline Challenge activity & 1.62 & 0.60 & 1.18 & 0.59 & 2.71 & 53 & $0.009 * *$ & 0.74 \\
\hline Challenge passivity & 1.48 & 0.61 & 1.28 & 0.67 & 1.03 & 53 & 0.308 & 0.31 \\
\hline Threat & 0.44 & 0.53 & 0.24 & 0.51 & 1.41 & 53 & 0.163 & 0.38 \\
\hline
\end{tabular}

${ }^{*} p<0.05 ;{ }^{*} p<0.01$; a statistically significant using the Benjamini-Hochberg procedure $p$ values from lowest to highest and compares them to a critical value $(i / m) Q$, where $i$ is the rank, $m$ is the total number of comparisons, and $Q$ is the false discovery rate (McDonald 2009). According to the procedure, the largest $p$ value that is smaller than $(i / m) Q$ is significant, and all of the $p$ values smaller than it are also significant. None of the obtained results is statistically significant using the Benjamini-Hochberg procedure with the false discovery rate set to $10 \%$.

\subsection{Conclusions}

As the improved freeze-frame stimulus did evoke a stronger experience of stress in the participants in the experimental group, we decided to check whether different stimuli matching the schema of a significant other would work similarly. Having had collected a lot of qualitative data from the firefighters in the qualitative study mentioned earlier (Strojny et al. 2018), we chose a different type of person, with whom the participants could make a bond. However, after correcting for multiple comparisons, the observed effects did not remain statistically significant, so these results should be interpreted with caution.

\section{Study III}

\subsection{Materials and methods}

\subsubsection{Participants}

Fifty-five firefighters (professionals: $n=7$, or cadets: $n=48$ ) participated in the described part of the study: 54 of them were men and one was a woman; their age ranged between 19 and $39(M=22.11, \mathrm{SD}=3.7)$. The length of service ranged between 1 and 19 years (cadets: $M=1.13$, $\mathrm{SD}=0.62$; professionals: $M=8.14, \mathrm{SD}=6.28$ ). They were the same individuals as in the first and second iteration, and the experimental conditions were kept consistent. Due to the absence of specific participants or their refusal to participate in the study, the descriptive statistics are different than in the previous iterations.

\subsubsection{Procedure}

In the third iteration of the study, more possible interactions with the victims were added. The participants could perform CPR and check the pulse of the victims. Moreover, they could perform passive oxygen therapy with the equipment from the medical bag.

The freeze-frame stimulus was changed to a white dress, resembling a bride's attire, covered in blood, as it corresponded to some extent with the interview quoted in Sect. 1.2. This item was placed inside the car, but was visible from the outside. It should be noted that the dress was a mesh without implemented gravity and could not be moved from its position. Sample screenshots of the simulator are presented in Fig. 4.

\subsubsection{Measures}

The self-report measures remained the same as the ones described in Sect. 2.1.3. Due to changed characteristics 


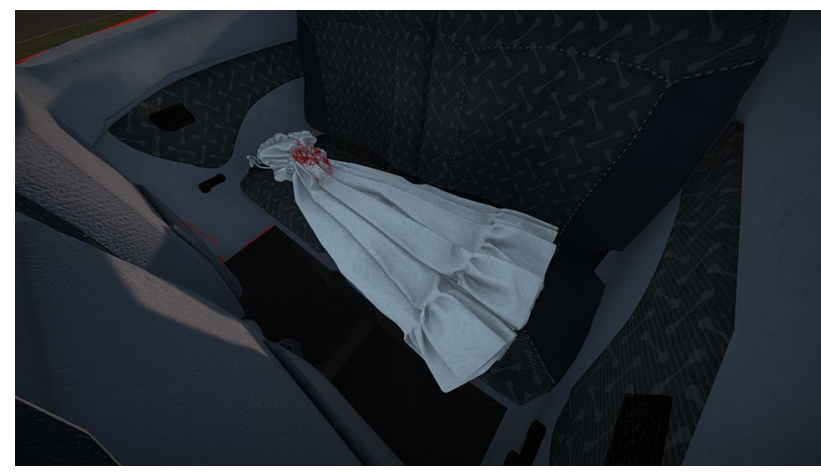

Fig. 4 The freeze-frame stimulus in the third iteration of the study-a bloodstained white dress on the car seat

of the stimuli, slight changes in the manipulation check were made. This time the participants were asked whether they had seen the following objects: an annoying witness, a drone, bystanders, a policeman, and a wedding dress. As before, some of the objects were stimuli in other experimental conditions and some of them were masking items.

\subsection{Results}

As it was done for the previous iterations, manipulation check was analyzed firstly. It was discovered that the majority of the participants ( 25 out of $30 ; 83.3 \%$ ) reported that they had not seen the wedding dress inside the car. However, as the dress was undoubtedly visible from many points of the environment, in which each of the participants had to be present during the task, we considered this result as unreliable and conducted the comparisons as planned. Several significant differences between the two groups were discovered. In particular, the two groups differed in terms of four emotions: fear, anger, guilt, and sadness. The participants in the experimental group reported higher levels of fear, anger, guilt, and sadness (see Table 3; for raw data see the Online Resource 2). Effect sizes were of high (for fear: $d=0.81$ ) and moderate (for anger: $d=0.62$, guilt: $d=0.78$, sadness: $d=0.66$ ) strength. No more significant differences between the conditions were found.

In this analysis, we also used the Benjamini-Hochberg procedure to adjust the $p$ values due to multiple comparisons being made. After this correction, with false discovery rate set to $10 \%$, the results described above remained statistically significant (fear: $0.005<0.008$, guilt: $0.005<0.015$, sadness: $0.020<0.023$, anger: $0.028<0.031)$.

\subsection{Conclusions}

The changes detected in negative emotions, namely the increased level of anger, sadness, guilt, and fear, are consistent with our predictions. It can be concluded that the wedding dress activated the cognitive schema of a significant other by evoking the aforementioned negative emotions.
Table 3 T test results comparing the experimental and control group on emotions, affect, and stress in the third iteration of the study

\begin{tabular}{|c|c|c|c|c|c|c|c|c|}
\hline & \multicolumn{2}{|c|}{ Experimental } & \multicolumn{2}{|c|}{ Control } & \multicolumn{3}{|l|}{$t$ test } & \multirow[t]{2}{*}{ Cohen's $a$} \\
\hline & $M$ & SD & $M$ & SD & $t$ & $d f$ & $p$ & \\
\hline \multicolumn{9}{|c|}{ Self-Assessment Manikin } \\
\hline Valence & 6.03 & 1.38 & 6.40 & 1.73 & 0.88 & 53 & 0.386 & 0.24 \\
\hline Arousal & 4.00 & 1.55 & 3.72 & 1.51 & 0.67 & 53 & 0.504 & 0.18 \\
\hline Dominance & 5.17 & 1.39 & 5.76 & 1.61 & 1.46 & 53 & 0.149 & 0.39 \\
\hline \multicolumn{9}{|l|}{ Scale of Emotions } \\
\hline Joy & 2.74 & 1.04 & 2.71 & 1.18 & 0.11 & 53 & 0.916 & 0.03 \\
\hline Love & 2.24 & 0.90 & 1.94 & 0.95 & 1.21 & 53 & 0.233 & 0.32 \\
\hline Fear & 2.15 & 0.89 & 1.53 & 0.61 & 3.06 & 51.28 & $0.005 * * \mathrm{a}$ & 0.81 \\
\hline Anger & 1.95 & 0.92 & 1.45 & 0.67 & 2.26 & 53 & $0.028 * * \mathrm{a}$ & 0.62 \\
\hline Guilt & 1.73 & 0.71 & 1.28 & 0.40 & 2.93 & 47.44 & $0.005^{* * a}$ & 0.78 \\
\hline Sadness & 1.60 & 0.58 & 1.26 & 0.44 & 2.40 & 53 & $0.02 * * \mathrm{a}$ & 0.66 \\
\hline \multicolumn{9}{|c|}{ Stress Appraisal Questionnaire } \\
\hline Harm/loss & 0.36 & 0.43 & 0.24 & 0.37 & 1.07 & 53 & 0.288 & 0.30 \\
\hline Challenge activity & 1.38 & 0.63 & 1.16 & 0.70 & 1.22 & 53 & 0.228 & 0.33 \\
\hline Challenge passivity & 1.30 & 0.63 & 1.26 & 0.86 & 0.18 & 53 & 0.859 & 0.05 \\
\hline Threat & 0.41 & 0.52 & 0.28 & 0.43 & 1.04 & 53 & 0.303 & 0.27 \\
\hline
\end{tabular}

${ }^{*} p<0.05 ;{ }^{*} p<0.01$; ${ }^{\text {a }}$ statistically significant using the Benjamini-Hochberg procedure 


\section{Discussion}

The study aimed to clarify whether the freeze-frame stimulus can activate the cognitive schema of a significant other. Based on the analysis of interviews, we hypothesized that freeze-frame objects may evoke specific emotions that are similar to those experienced during real rescue operations. In the course of the experimental study with three iterations, we tested two different types of freeze-frame stimuli representing significant others: objects associated with children (a toy, a sticker on a car, a child's seat) and with young women who have or will have gotten married in a recent time (a white dress).

The fact that the participants who had seen the freezeframe child stimulus experienced a higher level of stress (particularly, the challenge-activity and harm/loss dimensions) was consistent with our hypothesis. However, there is a chance that these discoveries are false positive (type I error), as the results of a multiple comparisons correction indicated that these results are not statistically significant. Despite this risk, it seems that these results are plausible, as the harm/loss dimension represents feelings of incurred loss regarding important objects and the challenge-activity dimension indicates a possibility of overcoming a difficult situation while perceiving one's coping abilities and competences as good (Włodarczyk and Wrześniewski 2010). As such, these interpretations seem to be consistent with our assumptions that thinking that a child is present at the accident site will heighten the stress levels of the participants. These feelings may also be connected to evoking the cognitive schema of a significant other. Contrary to our hypotheses, we did not detect any differences between the two groups in terms of emotions. Neither negative emotions (fear, anger, guilt, and sadness) increased nor positive emotions (joy, love) decreased under the influence of childassociated freeze-frame stimulus.

The influence of the freeze-frame stimulus on situational stress appraisal was not replicated in the third iteration, where we detected differences in negative emotions. Placing a wedding dress evoked changes in terms of fear, anger, guilt, and sadness even though the majority ( 25 of 30 ) of participants reported that they had not seen the wedding dress. However, the Benjamini-Hochberg procedure shows that results remain statistically significant even after correcting for multiple comparisons. There were no significant differences between the experimental and control group in terms of positive emotions. Interestingly, as it was mentioned above, in the two iterations where significant differences between groups were observed, they regarded different types of affective states. For the child stimulus, in the experimental group, an elevated level of active challenge and feelings of harm and loss was observed, whereas for the wedding dress stimulus we observed stronger negative emotions: fear, anger, guilt, and sadness. Nonetheless, there may be a plausible explanation for this observation. Children are highly specific victims, as they require different doses of medicines and sometimes different procedures. Even the CPR procedure is different for children than adults (O'Connor 2019). In the case of adults, the optimal compression to ventilation ratio is 30:2 (Yannopoulos et al. 2006). However, in the case of children, this ratio is strongly dependent on the body weight and it has to be calculated ad hoc (Babbs and Nadkarni 2004). Having said that, the presence of a child on an accident site may cause firefighters to switch to the specific processing mode-hence the elevated feelings of challenge. Thinking that a helpless child had been harmed in an accident could have as well caused the harm and loss experience. Another explanation is that the childassociated object triggered the freezing reaction, which, as we mentioned in the Introduction section, is rather an active state of preparation than a passive mode (Ly et al. 2017). Therefore, it could be expected that the experience of stress and active challenge would be elevated in this case. Moreover, no child was present in our simulator, so the suggestion of its presence might have caused the participants of the study to start actively searching for the baby. No systematic observations were conducted on this matter; however, the experimenters did notice such behavior in some of the participants. At least two of them reported, after the study, that when they noticed the toy, they started to search for the child and that deterred them from other actions. It would certainly be interesting and valuable for further studies to record such nuanced changes in behavior-recording the experimental task or using eye-tracking techniques combined with a postexperiment interview with the participant could provide more insight into this matter.

For the wedding dress stimulus, the situation was slightly different. On the simulated accident site, there were several adult women present, so the participants could have concluded that the wedding dress belonged to one of them. Therefore, there was no need to search for further undiscovered victims and to think about different values of life parameters, as even if there was another victim, she would have been an adult. However, the wedding dress added personal context to the scene, and as a result, we observed an increase in negative emotions for the experimental group when compared to the control one. It appears to be consistent with our assumptions that evoking the schema of a significant other was connected with experiencing negative emotions, such as fear, anger, guilt, and sadness. Based on the results, it can be concluded that some affective states associated with seeing a person resembling a significant other on the accident site can be evoked in a VR simulation. This activation in turn increases the psychological fidelity of the simulation. The psychological fidelity is not only the 
extent to which emotions and other psychological factors can be replicated during VR training, but it also indicates which emotions can be evoked during a real action with a similar context. As it was more broadly described above, we discovered that different types of stimuli can evoke different emotional states in a virtual environment.

In reported studies, we were not able to evoke changes in terms of positive emotions' (joy, love) decrease in the experimental group. As odd as it may seem to observe differences in negative emotions and no differences in positive emotions, there may be an explanation. Different types of valence (positive or negative) may be associated with different patterns of autonomic nervous system (ANS, Levenson 1992). Particularly, it was discovered that negative emotions are characterized by higher ANS activity than positive emotions (Ekman et al. 1983; Fredrickson 1998). Therefore, our freeze-frame stimuli may be too subtle to evoke a decrease in positive emotions.

Another issue that appears to be worth discussing regarding the reported study is the importance of manipulation checks in psychological research. Employing the manipulation check in our study proved to be more problematic than expected. We experienced two cases of "failed manipulation checks," but in one of them, significant differences between analyzed groups did exist. In the first iteration of our study, the manipulation check revealed that most of the participants in the experimental group did not see the freeze-frame stimulus (the child's toy), which was followed by a lack of statistically significant differences between the two analyzed groups. However, a similar situation occurred in the third iteration of the study - once more, the majority of the participants reported that they had not seen the freeze-frame stimulus (in this case, the wedding dress), but this time we discovered several expected significant differences between the two groups in terms of emotions. These results were consistent with the hypothesis, and they regarded several variables, all of them representing negative emotions. Therefore, we wondered whether the manipulation checks in the form of self-report do provide important information about the perception of the stimuli, whether they should or should not be used, and whether the results we achieved could be an artifact.

Despite the failed manipulation checks, years of research on pre-attentive processing (e.g., Appelbaum and Norcia 2009), affective priming (Murphy and Zajonc 1993), and inattentional blindness (Simons and Chabris 1999) suggest that it is possible that unnoticed stimuli, in fact, influence human reactions. Moreover, in a seminal work, Sigall and Mills (1998) argued that the effect of experimental manipulation exists whenever "there is no plausible alternative explanation" (Sigall and Mills 1998, p. 223). There is a chance that the discovered significant differences are a result of type I error. The probability of committing such error increases when a large number of variables is tested (Dudoit et al. 2004). Therefore, we tested our results using the Benjamini-Hochberg procedure. Based on the comparison between obtained $p$ values and the Benjamini-Hochberg critical values, it may be concluded that the manipulation did evoke the intended emotional response in the third iteration. Unfortunately, the results obtained in the second iteration of the study are not significant in light of the Benjamini-Hochberg correction. Therefore, we cannot clearly state that the child stimulus evoked the intended response. However, seeing coherent results on scales measuring similar or complementary constructs and discovering medium or large effect sizes act, in our opinion, in favor of the research hypothesis confirmation.

Despite the points raised above, one could wonder why the participants in our study did not see the stimuli implemented in the virtual environment. One possible explanation is that they were focused on other elements present in their field of view and simply overlooked other stimuli. However, care was taken to locate the stimuli in places that should be carefully examined during a rescue action (inside the car wreck or next to it). As it is an imperfect method and no data were collected on which objects were present in participants' field of view, it cannot be said with certainty that they were seen. Therefore, in further studies on the topic logs on which objects were present in participants' point of view should be gathered.

The "teleportation" movement mode could also be responsible for missing some of the elements present on the scene. When a participant "jumped" from one corner of the scene to another, they could have missed several details of the environment simply because they did not even appear in their field of view. What is more, VR headsets have a significantly smaller field of view angle when compared to the natural range of human eyes $\left(110^{\circ}\right.$ for HTC Vive ${ }^{5}$ and approx. $210^{\circ}$ for human eyes). Therefore, what can be seen in a virtual environment does not entirely cover the extent of what could be seen and fewer details can be present in the available field of view. This issue, however, will always happen when using head-mounted displays-the widest field of view available now for a VR headset is $200^{\circ}\left(170^{\circ}\right.$ horizontal and $130^{\circ}$ vertical) offered by Pimax $8 \mathrm{~K} .{ }^{6}$ The more popular headsets offer the field of view angle around $100^{\circ}\left(100^{\circ}\right.$ for PlayStation $\mathrm{VR}^{7}$ and $90^{\circ}$ horizontal and $110^{\circ}$ diagonal for Oculus Rift $^{8}$ ).

\footnotetext{
5 Source: https://www.vive.com/us/comparison/.

${ }^{6}$ Source: https://www.pimax.com/pages/pimax-8k-series.

${ }^{7}$ Source: https://www.playstation.com/explore/playstation-vr/tech-specs/.

${ }^{8}$ Source: https://en.wikipedia.org/wiki/Oculus_Rift.
} 
As it was discussed by Arias et al. (2019), the difference between the natural field of view and the field of view provided by the VR headset may be too big to draw exact comparisons between real-life behavior and actions taken in a virtual environment. In light of the aforementioned limitations of VR technology, even more care should be taken to make sure that all experimental manipulation is distinct enough to be noticed by the participants. On the other hand, some studies suggest that real-life emotions or social responses can be evoked in a virtual environment (e.g., embarrassment-Slater, Sadagic, Usoh and Schroeder 2000; fear-Lin 2017; fear and changes in self-confidence during speaking in front of a virtual audience-Pertaub, Slater and Barker 2001, 2002).

Regarding the cognitive schemas, our study supports the claim that it is possible to activate them in a VR simulation using perceptual stimuli. In particular, we were able to activate the schema of a significant other-when the stimuli were strong and suggestive enough, they evoked emotions and experience of stress. We confirmed that for stimuli regarding two different categories of significant others-children and soon-to-be brides/newlyweds. However, the response differed between the stimuli-the child stimulus evoked an experience of stress, whereas the bride-to-be stimulus evoked negative emotions.

What is more, there are other situations that could be extremely difficult to cope with-for instance, seeing injured co-workers, family members, or victims similar to the rescuer themselves (e.g., Berninger et al. 2010; Cetin et al. 2005; Huang et al. 2013). It seems to be crucial to prepare trainees for such situations as early in the training process as possible (Ben-Ezra et al. 2005; Ly et al. 2017). Undoubtedly, there are no easy ways to prepare trainees for such events, especially in traditional training. VR simulators could be useful for that to some extent, as they allow for easy and relatively low-cost modification of the presented stimuli.

Summing up, we can conclude that adding the freezeframe stimuli works in favor of elevating the psychological fidelity of the simulation. As we have stated in Sect. 1.2, such fidelity is crucial for skill and knowledge transfer, especially in light of mood-state dependency (Blaney 1986). Our stimuli evoked negative emotions and feelings of challenge and harm or loss; therefore, we can say that the training situation was perceived not so much as a fun game and more as an actual training or an approximated projection of a rescue operation.

Acknowledgements This work was supported by the Polish National Centre for Research and Development under the grant "Widespread Disaster Simulator - research and preparation for implementation" (Project Number POIR.01.01.01-00.0042/16; the Smart Growth Operational Programme, sub-measure 1.1.1. Industrial research and development work implemented by enterprises) received by Nano Games sp. z o.o. The authors would like to thank Radosław Sterna, Krzysztof
Rębilas, and Bartosz Wojciechowski for their help with the data acquisition, Gabriela Czarnek for sharing her methodological knowledge in the process of designing the procedure, Konrad Klocek and the whole Nano Games programming team for creating the VR simulator used in the study, Alicja Mrocheń for her help with preparing the graphics, and Barbara Giżycka for proofreading the article.

Authors' contributions NL wrote a major part of the paper (a major part of Introduction, Methods, Results, and Discussion sections) and conducted main statistical analyses. NDM wrote a minor part of the paper (a part of Methods and Discussion), conducted a literature research, and conducted additional statistical analyses. AS contributed to the design of the study and provided important psychological insight into the Introduction and Discussion section. PS wrote a part of the theoretical section, contributed to the design of the paper, and provided the final revision of the text. All authors listed have made considerable intellectual contribution to the work, revised the manuscript, and read and approved the submitted version.

Funding This work was supported by the Polish National Centre for Research and Development under the grant "Widespread Disaster Simulator - research and preparation for implementation" (project number POIR.01.01.01-00.0042/16; the Smart Growth Operational Programme, sub-measure 1.1.1. Industrial research and development work implemented by enterprises) received by Nano Games sp. z o.o.

Availability of data and materials We include raw data to the electronic supplementary materials.

\section{Compliance with ethical standards}

Conflict of interest The authors declare that the research was conducted in the absence of any commercial or financial relationships that could be construed as a potential conflict of interest. However, as the connection between the authors and a commercial company could be viewed as one, it was decided to provide more arguments in this matter. Firstly, the VR simulator described in the study may (and most probably will) be commercialized in the future. However, the R\&D team is not responsible for sales and marketing in any way. The primary goal of the present paper is of purely research nature, both basic and applied. It could be used as an argument for the substantive value of the simulators as well. The project is co-founded by the National Centre for Research and Development in Poland and the structure of the grant proposal required pre-planning of any empirical studies to be conducted and declaration of intention to publish the results. The research part of the project was viewed as an important one, and the results of it are valuable separately from any future sales results. All information about the study design, the data collected during the experiment, and not only the confirmed hypotheses, but also the ones that were not confirmed in the study, is provided in the article text and the Supplementary Materials. The authors believe that this enhances the transparency of the presented study.

Open Access This article is licensed under a Creative Commons Attribution 4.0 International License, which permits use, sharing, adaptation, distribution and reproduction in any medium or format, as long as you give appropriate credit to the original author(s) and the source, provide a link to the Creative Commons licence, and indicate if changes were made. The images or other third party material in this article are included in the article's Creative Commons licence, unless indicated otherwise in a credit line to the material. If material is not included in the article's Creative Commons licence and your intended use is not permitted by statutory regulation or exceeds the permitted use, you will 
need to obtain permission directly from the copyright holder. To view a copy of this licence, visit http://creativecommons.org/licenses/by/4.0/.

\section{References}

Alexander AL, Brunyé T, Sidman J, Weil SA (2005) From gaming to training: a review of studies on fidelity, immersion, presence, and buy-in and their effects on transfer in PC-based simulations and games. DARWARS Training Impact Group 5:1-14

Andersen SM, Reznik I, Manzella LM (1996) Eliciting facial affect, motivation, and expectancies in transference: significant-other representations in social relations. J Pers Soc Psychol 71:1108-1129

Appelbaum LG, Norcia AM (2009) Attentive and pre-attentive aspects of figural processing. J Vis 9:18. https://doi.org/10.1167/9.11.18

Arias S, La Mendola S, Wahlqvist J, Rios O, Nilsson D, Ronchi E (2019) Virtual reality evacuation experiments on way-finding systems for the future circular collider. Fire Technol 55:2319-2340

Axelrod R (1973) Schema theory: an information processing model of perception and cognition. Am Polit Sci Rev 67:1248-1266

Azevedo TM, LA Volchan Imbiriba, Rodrigues EC, Oliveira JM, Oliveira LF, Lutterbach LG, Vargas CD (2005) A freezing-like posture to pictures of mutilation. Psychophysiology 42:255-260

Babbs CF, Nadkarni V (2004) Optimizing chest compression to rescue ventilation ratios during one-rescuer CPR by professionals and lay persons: children are not just little adults. Resuscitation 61:173-181

Beaton R, Murphy S, Johnson C, Pike K, Corneil W (1998) Exposure to duty-related incident stressors in urban firefighters and paramedics. J Traumatic Stress 11:821-828

Beaudoin P, Paquet S, Poulin P (2001) Realistic and controllable fire simulation. Graphics Interface 2001:159-166

Ben-Ezra M, Essar N, Saar R (2005) Post-traumatic reactions among rescue personnel 96 hours after the Hilton Hotel bombing in Sinai: the effect of previous exposure. Stress Health J Int Soc Investig Stress 21:269-272

Benjamini Y, Hochberg Y (1995) Controlling the false discovery rate: a practical and powerful approach to multiple testing. J R Stat Soc Ser B (Methodol) 57(1):289-300

Berninger A, Webber MP, Cohen HW, Gustave J, Lee R, Niles JK, Prezant DJ (2010) Trends of elevated PTSD risk in firefighters exposed to the World Trade Center disaster: 2001-2005. Public Health Rep 125:556-566

Blaney PH (1986) Affect and memory: a review. Psychol Bull 99:229-246

Brackney DE, Priode K (2017) Back to reality: the use of the presence questionnaire for measurement of fidelity in simulation. J Nurs Meas 25(2):66E-73E

Bradley MM, Lang PJ (1994) Measuring emotion: the self-assessment manikin and the semantic differential. J Behav Ther Exp Psychiatry 25:49-59. https://doi.org/10.1016/0005-7916(94)90063-9

Brooks SK, Dunn R, Amlôt R, Greenberg N, Rubin GJ (2016) Social and occupational factors associated with psychological distress and disorder among disaster responders: a systematic review. BMC Psychol 4:18

Carey MG, Al-Zaiti SS, Dean GE, Sessanna L, Finnell DS (2011) Sleep problems, depression, substance use, social bonding, and quality of life in professional firefighters. J Occup Environ Med/Am Coll Occup Environ Med 53:928

Cetin M, Kose S, Ebrinc S, Yigit S, Elhai JD, Basoglu C (2005) Identification and posttraumatic stress disorder symptoms in rescue workers in the Marmara, Turkey, earthquake. J Traumatic Stress 18:485-489
Cohen J (1988) The t test for means. In: Cohen J (ed) Statistical power analysis for the behavioral sciences. Hillsdale, Erihaum, pp 19-74

Cohen J (1992) A power primer. Psychol Bull 112:155-159

De Soir E, Knarren M, Zech E, Mylle J, Kleber R, Van der Hart O (2012) A phenomenological analysis of disaster-related experiences in fire and emergency medical services personnel. Prehosp Disaster Med 27:115-122

Derry SJ (1996) Cognitive schema theory in the constructivist debate. Educ Psychol 31:163-174. https://doi.org/10.1080/00461 520.1996.9653264

Deterding S, Dixon D, Khaled R, Nacke L (2011) From game design elements to gamefulness: defining" gamification". In: Proceedings of the 15th international academic MindTrek conference: envisioning future media environments, pp 9-15

Dudoit S, van der Laan MJ, Pollard KS (2004) Multiple testing. Part I. Single-step procedures for control of general type I error rates. Stat Appl Genet Mol Biol 3:1-69

Ekman P, Levenson RW, Friesen WV (1983) Autonomic nervous system activity distinguishes among emotions. Science 221:1208-1210

Evans TR (2019) Emotions in the fire service: decision-making, risk, and coping. In: Applying occupational psychology to the Fire Service. Palgrave Macmillan, Cham, pp 13-57

Fabricatore C, López X, Fabricatore C (2014) Using gameplay patterns to gamify learning experiences. In: ECGBL2014-8th European Conference on Games Based Learning: ECGBL2014, p 110

Fiske ST, Taylor SE (1991) Social cognition. Mcgraw-Hill Book Company, New York

Fredrickson BL (1998) What good are positive emotions? Rev Gen Psychol 2:300-319

Gladwin TE, Hashemi MM, van Ast V, Roelofs K (2016) Ready and waiting: freezing as active action preparation under threat. Neurosci Lett 619:182-188

Glocker ML, Langleben DD, Ruparel K, Loughead JW, Gur RC, Sachser N (2009) Baby schema in infant faces induces cuteness perception and motivation for caretaking in adults. Ethology 115:257-263

Gormley M, Walsh T, Fuller R (2008) Risks in the driving of emergency service vehicles. Irish J Psychol 29:7-18. https://doi. org/10.1080/03033910.2008.10446270

Graafland M, Schraagen JM, Schijven MP (2012) Systematic review of serious games for medical education and surgical skills training. Br J Surg 99:1322-1330. https://doi.org/10.1002/bjs.8819

Hagenaars MA, Roelofs K, Stins JF (2014) Human freezing in response to affective films. Anxiety Stress Coping 27:27-37

Han PH, Chen YS, Lee KC, Wang HC, Hsieh CE, Hsiao JC, Chou CH Hung YP (2018) Haptic around: multiple tactile sensations for immersive environment and interaction in virtual reality. In: Proceedings of the 24th ACM symposium on virtual reality software and technology, pp 1-10

Haque S, Srinivasan S (2006) A meta-analysis of the training effectiveness of virtual reality surgical simulators. IEEE Trans Inf Technol Biomed 10:51-58. https://doi.org/10.1109/TITB.2005.855529

Hoffman B, Nadelson L (2010) Motivational engagement and video gaming: a mixed methods study. Educ Tech Res Dev 58:245270. https://doi.org/10.1007/s11423-009-9134-9

Hommel B (1996) The cognitive representation of action: automatic integration of perceived action effects. Psychol Res 59:176-186

Huang J, Liu Q, Li J, Li X, You J, Zhang L, Luan R (2013) Posttraumatic stress disorder status in a rescue group after the Wenchuan earthquake relief. Neural Regener Res 8:1898-1906

Jahnke SA, Poston WSC, Haddock CK, Jitnarin N (2013) Obesity and incident injury among career firefighters in the central United States. Obesity 21:1505-1508 
Johnsen K, Dickerson R, Raij A, Lok B, Jackson J, Shin M, Hernandez J, Stevens A, Lind DS (2005) Experiences in using immersive virtual characters to educate medical communication skills. In: IEEE proceedings. VR 2005, virtual reality, 2005, pp 179-186. https://doi.org/10.1109/VR.2005.1492772

Katsavouni F, Bebetsos E, Malliou P, Beneka A (2016) The relationship between burnout, PTSD symptoms and injuries in firefighters. Occup Med 66:32-37

Levenson RW (1992) Autonomic nervous system differences among emotions. Psychol Sci 3:23-27

Lin JHT (2017) Fear in virtual reality (VR): fear elements, coping reactions, immediate and next-day fright responses toward a survival horror zombie virtual reality game. Comput Hum Behav 72:350-361

Lourel M, Abdellaoui S, Chevaleyre S, Paltrier M, Gana K (2008) Relationships between psychological job demands, job control and burnout among firefighters. N Am J Psychol 10:489-496

Ly V, Roijendijk L, Hazebroek H, Tonnaer C, Hagenaars MA (2017) Incident experience predicts freezing-like responses in firefighters. PLoS ONE 12:e0186648

McDonald JH (2009) Handbook of biological statistics, vol 2. Sparky House Publishing, Baltimore, pp 6-59

Miesler L, Leder H, Herrmann A (2011) Isn't it cute: an evolutionary perspective of baby-schema effects in visual product designs. Int J Des 5(3): 17-30

Monteiro JK, Abs D, Labres ID, Maus D, Pioner T (2013) Firefighters: psychopathology and working conditions. Estudos de Psicologia (Campinas) 30:437-444

Murphy ST, Zajonc RB (1993) Affect, cognition, and awareness: affective priming with optimal and suboptimal stimulus exposures. J Pers Soc Psychol 64:723. https://doi. org/10.1037/0022-3514.64.5.723

O'Connor RE (2019) Cardiopulmonary resuscitation (CPR) in infants and children. MSD Manual professional version. https ://www.msdmanuals.com/professional/critical-care-medicine/ cardiac-arrest-and-cpr/cardiopulmonary-resuscitation-cpr-ininfants-and-children. Accessed 29 Jan 2020

Peirce JW (2007) Psychopy—psychophysics software in python. J Neurosci Methods 162:8-13. https://doi.org/10.1016/j.jneum eth.2006.11.017

Peirce JW (2009) Generating stimuli for neuroscience using psychopy. Front Neuroinform 2:10. https://doi.org/10.3389/neuro .11.010.2008

Pertaub DP, Slater M, Barker C (2001) An experiment on fear of public speaking in virtual reality. Stud Health Technol Inform 81:372-378

Pertaub DP, Slater M, Barker C (2002) An experiment on public speaking anxiety in response to three different types of virtual audience. Presence Teleoper Virtual Environ 11(1):68-78

Regehr C, Hill J, Knott T, Sault B (2003) Social support, self-efficacy and trauma in new recruits and experienced firefighters. Stress Health 19:189-193

Rosser JC, Lynch PJ, Cuddihy L, Gentile DA, Klonsky J, Merrell R (2007) The impact of video games on training surgeons in the 21st century. Arch Surg 142:181-186. https://doi.org/10.1001/ archsurg.142.2.181

Sigall H, Mills J (1998) Measures of independent variables and mediators are useful in social psychology experiments: but are they necessary? Pers Soc Psychol Rev 2:218-226. https://doi.org/10.1207/ s15327957pspr0203_5

Simons DJ, Chabris CF (1999) Gorillas in our midst: sustained inattentional blindness for dynamic events. Perception 28:1059-1074. https://doi.org/10.1068/p281059
Slater M, Sadagic A, Usoh M, Schroeder R (2000) Small-group behavior in a virtual and real environment: a comparative study. Presence Teleoper Virtual Environ 9:37-51

Smith JA, Shinebourne P (2012) Interpretative phenomenological analysis. American Psychological Association, Washington

Smith TD, Hughes K, DeJoy DM, Dyal MA (2018) Assessment of relationships between work stress, work-family conflict, burnout and firefighter safety behavior outcomes. Saf Sci 103:287-292

Strojny P, Strojny A, Kałwak W, Bańbura A (2018) Take your eyes off me. The effect of the presence of witnesses on the conduct of rescue operations. Bezpieczeństwo i Technika Pożarnicza 49:14-22. https://doi.org/10.12845/bitp.49.1.2018.1

Supreme Audit Office (2012) Funkcjonowanie szkół i ośrodków szkoleniowych w Policji, Państwowej Straży Pożarnej i Straży Granicznej [eng. Functioning of schools and training centers in the Police, State Fire Service and Border Guard]

Tesser A, Leone C (1977) Cognitive schemas and thought as determinants of attitude change. J Exp Soc Psychol 13:340-356. https:// doi.org/10.1016/0022-1031(77)90004-X

The State Fire Service of Poland (2016) Program szkolenia podstawowego w zawodzie strażak [eng. Basic training programme for the firefighter profession]. https://www.straz.gov.pl/panstwowa straz_pozarna/Ksztalcenie_w_PSP. Accessed 19 Jan 2020

The State Fire Service of Poland (2018) Stan wypadkowości w PSP i OSP [eng. Accidents in State Fire Service]. Information bulletin of the State Fire Service for the year 2018

Ucros CG (1989) Mood state-dependent memory: a meta-analysis. Cogn Emot 3(2):139-169

Wagner SL, McFee JA, Martin CA (2010) Mental health implications of fire service membership. Traumatology 16:26-32

Williams-Bell FM, Kapralos B, Hogue A, Murphy BM, Weckman EJ (2015) Using serious games and virtual simulation for training in the fire service: a review. Fire Technol 51:553-584

Włodarczyk D, Wrześniewski K (2010) Kwestionariusz oceny stresu (KOS) [eng. The Stress Appraisal Questionnaire (SAQ)]. Przegląd Psychologiczny 53:479-496

Wojciszke B, Baryła W (2005) Skale do pomiaru nastroju i sześciu emocji [eng. Scales for the measurement of mood and six emotions]. Czasopismo Psychologiczne-Psychol J 11:31-47

Woodall SJ (1997) Hearts on fire: an exploration of the emotional world of firefighters. Clin Sociol Rev 15:153-162

Wyer RS Jr, Bodenhausen GV, Srull TK (1984) The cognitive representation of persons and groups and its effect on recall and recognition memory. J Exp Soc Psychol 20:445-469

Yannopoulos D, Aufderheide TP, Gabrielli A, Beiser DG, McKnite SH, Pirrallo RG, Wigginton J, Nadkarni VM (2006) Clinical and hemodynamic comparison of 15:2 and 30:2 compression-to-ventilation ratios for cardiopulmonary resuscitation. Crit Care Med 34:1444-1449

Zasady organizacji ratownictwa medycznego w krajowym systemie ratowniczo-gaśniczym [eng. Principles of organization of emergency medical services in the rescue and firefighting system] (2013) https://www.straz.gov.pl/download/1854. Accessed 26 June 2019

Publisher's Note Springer Nature remains neutral with regard to jurisdictional claims in published maps and institutional affiliations. 